\title{
SOLARUPDATE
}

\section{Newsletter of the}

International Energy

Agency Solar Heating

and Cooling Programme
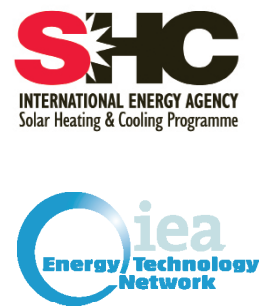

5

\#SolarThermal

\#SolarProcessHeat

\#SolarCooling

\#SolarDistrictHeating

\section{In This Issue}

\section{Solar Heat}

Worldwide Report

New Storage Task

Country Highlight:

United Kingdom

Interview: David Rennè

\&. Task 46

SHC 2017

2017 Solar Thermal Trends

SHC Solar Academy

Task 54: SHW Micro System

Task 54: LCOH

SHC Book Series

\section{Solar Heat Worldwide}

\section{Report Shows A Shifting Market}

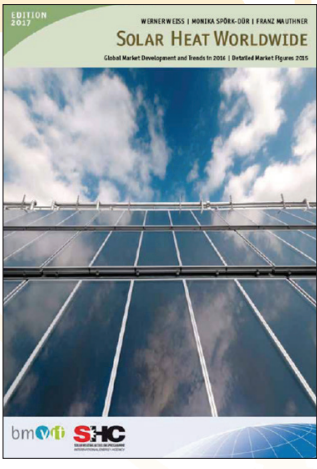

The IEA SHC Programme's report, Solar Heat Worldwide, is the most comprehensive publication on the global solar heating and cooling market. This year's report includes data from 66 countries, or $95 \%$ of the solar thermal market.

Since 2000, the global solar thermal capacity of unglazed and glazed water collectors in operation has grown seven fold - from 62 GWth (89 million square meters) in 2000 to $456 \mathrm{GW}$ th (652 million square meters) in 2016 . The corresponding annual solar thermal energy yields totaled 52 TWh in 2000 and 375 TWh in 2016.

Despite these achievements, the global solar thermal market has faced challenging times in recent years, particularly in the largest markets of China and Europe. In these markets, the traditional mass markets for small-scale solar water heating systems for detached single-family houses and apartment buildings are competing with the growing heat pump and photovoltaic system markets. The most dramatic drop has been in China where for the third year in a row the solar thermal market has declined. Although the big markets weakened, the markets grew in India, some Latin American countries, and to a certain extent in Sub-Sahara Africa.

In contrast to the small-scale solar water heating system market, the markets for megawatt-scale solar supported district heating systems and industrial applications have gained increasing support all over the world in recent years, and several ambitious projects have been successfully implemented. The most successful example in this respect is Denmark. In 2016 alone, 31 solar district heating plants

\section{"Heating accounts for 47\% of the world's energy} demand, which is higher than the combined demand for electricity (17\%) and transport (27\%). So it's important to remind ourselves that the huge potential of this renewable energy source is just waiting to be exploited."

KEN GUTHRIE IEA SHC Chairman
SHC Members

Australia

Austria

Belgium

Canada

China

Denmark

ECREEE

European

Commission

European Copper Institute

France

Germany GORD

ISES

Italy

Mexico

Netherlands

Norway

Portugal

RCREEE

Slovakia

South Africa

Spain

Sweden

Switzerland

Turkey

United Kingdom 
Solar Heat Worldwide from page I

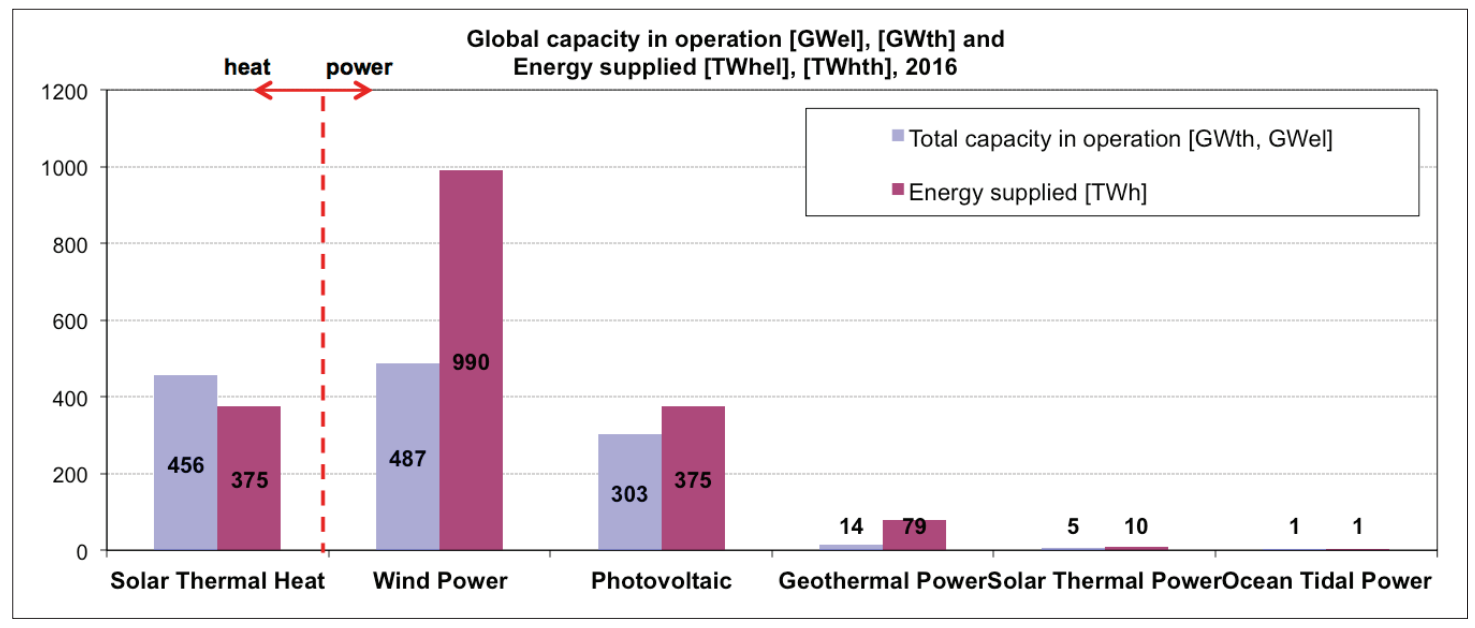

4 Figure I. Global capacity in operation and energy supplied in 2016. (Sources: AEE INTEC, Global Wind Energy Council (GWEC), European PV Industry Association (EPIA), REN2I - Global Status Report 2016)

- China
Europe
USA / Canada
Asia excl. China
$\square$ Latin America
$\square$ MENA Region
Australia / NZ
Sub-Sahara Africa
$\square$ Other countries

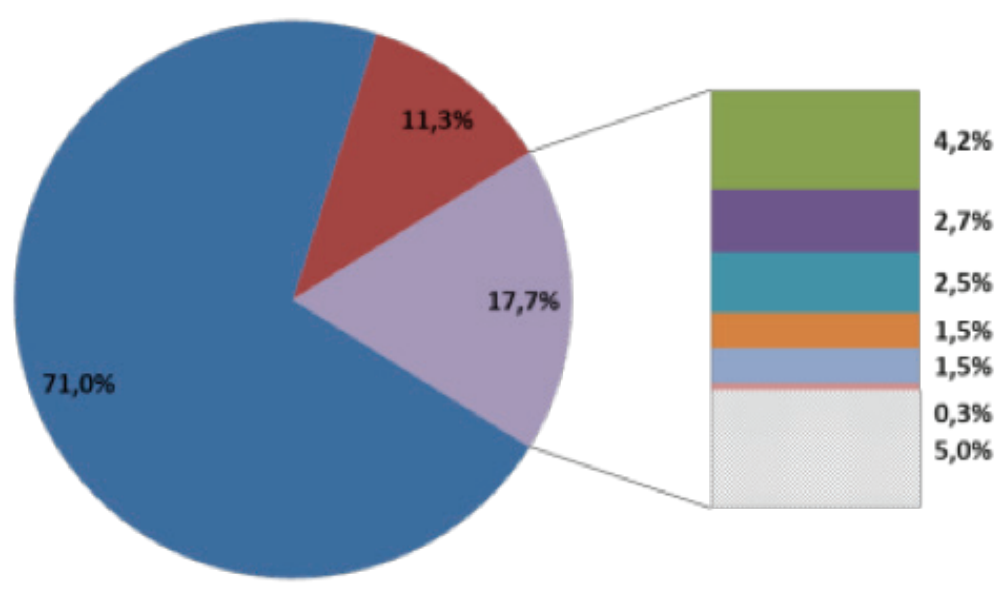

Sub-Sahara Africa: Botswana, Burkina Faso, Ghana, Lesotho, Mauritius, Mozambique, Namibia, Nigeria, Senegal, South Africa, Zimbabwe

Asia excluding China: India, Japan, Korea South, Taiwan, Thailand

Latin America: $\quad$ Barbados, Brazil, Chile, Mexico, Uruguay

Europe: $\quad$ EU 28, Albania, Macedonia, Norway, Russia, Switzerland, Turkey

MENA region: Israel, Lebanon, Palestinian Territories, Tunisia

In the global solar thermal markets two trends have become visible in recent years. The first is the shift of the strong markets from OECD countries to non-OECD countries. The second trend is a shrinking interest in the smallscale applications like domestic hot water systems and a growing interest in large-scale applications like solar district heating and industrial process heat. 
Solar Heat Worldwide from page 2

were installed and 5 existing plants were extended. The total installed capacity in operation in Denmark in solar district heating equaled 922 MWth $\left(1,317,635 \mathrm{~m}^{2}\right)$.

Compared with other forms of renewable energy, excluding traditional renewable energies like biomass and hydropower, solar heating's contribution to the global energy demand is second only to wind power (Figure I). When considering installed capacity, solar thermal is the leader.

\section{HIGHLIGHTS FROM THIS YEAR'S REPORT Total Capacity}

The vast majority of the $435.8 \mathrm{GW}$ th installed capacity in 2015 was installed in China (309.5 GWth) and Europe (49.2 GWth), which together accounted for $82 \%$ of the total capacity installed.

\section{Market Growth}

In 2015, a total capacity of $40.2 \mathrm{GW}$ th, corresponding to 57.4 million square meters of solar collectors, was installed worldwide, which represents a 14\% decrease compared to 2014.

Of the top 10 markets in 2015, growth was reported from India (+31.8\%), Turkey (+10\%), Israel (+9.5\%), Mexico (+7.8\%) and
Poland (+6.5\%). The other major solar thermal markets saw a decline, China (-17\%), Australia (-10.1\%), Germany (-9.7\%), Brazil $(-2.7 \%)$ and the United States (-0.7\%).

\section{Environmental Impact \& Jobs}

The energy produced by solar thermal applications in 2016 corresponds to a savings of 40.3 million tons of oil and 130 million tons of $\mathrm{CO} 2$.

The number of jobs globally in the fields of production, installation and maintenance of solar thermal systems is estimated to be $7 \mid 4,000$ in 2015.

\section{Applications}

On the technology side, evacuated tube collectors are the clear market leader accounting for $75.1 \%$ of the newly installed capacity, which is driven by the dominance of the Chinese market, followed by flat-plate collectors (20.8\%), unglazed water collectors (3.9\%), and unglazed and glazed air collectors (0.2\%).

The 2017 edition of the Solar Heat Worldwide report will be available June 2017 on the IEA SHC website,

http://www.iea-shc.org/solar-heat-worldwide.

\section{Top 10}

\begin{tabular}{|c|}
\hline $\begin{array}{l}\text { Installed Capacity } \\
\text { in } \mathbf{2 0 1 5} \\
\text { (in MWth) }\end{array}$ \\
\hline China 309, 470 \\
\hline United States 17,307 \\
\hline Turkey 13,637 \\
\hline Germany 13,226 \\
\hline Brazil 8,669 \\
\hline India 6,246 \\
\hline Australia 6,024 \\
\hline Austria 3,652 \\
\hline Israel 3,194 \\
\hline Greece 3,088 \\
\hline
\end{tabular}

\begin{tabular}{l} 
Installed Capacity per \\
$\mathbf{1 , 0 0 0}$ inhabitants in \\
$\mathbf{2 0 1 5}$ \\
(in kWth) \\
\hline Barbados 489 \\
Austria 421 \\
Cyprus 400 \\
Israel 397 \\
Greece 287 \\
Palestinian \\
Territories 276 \\
Australia 265 \\
China 226 \\
Turkey 172 \\
Germany 164
\end{tabular}

\section{Top 10}

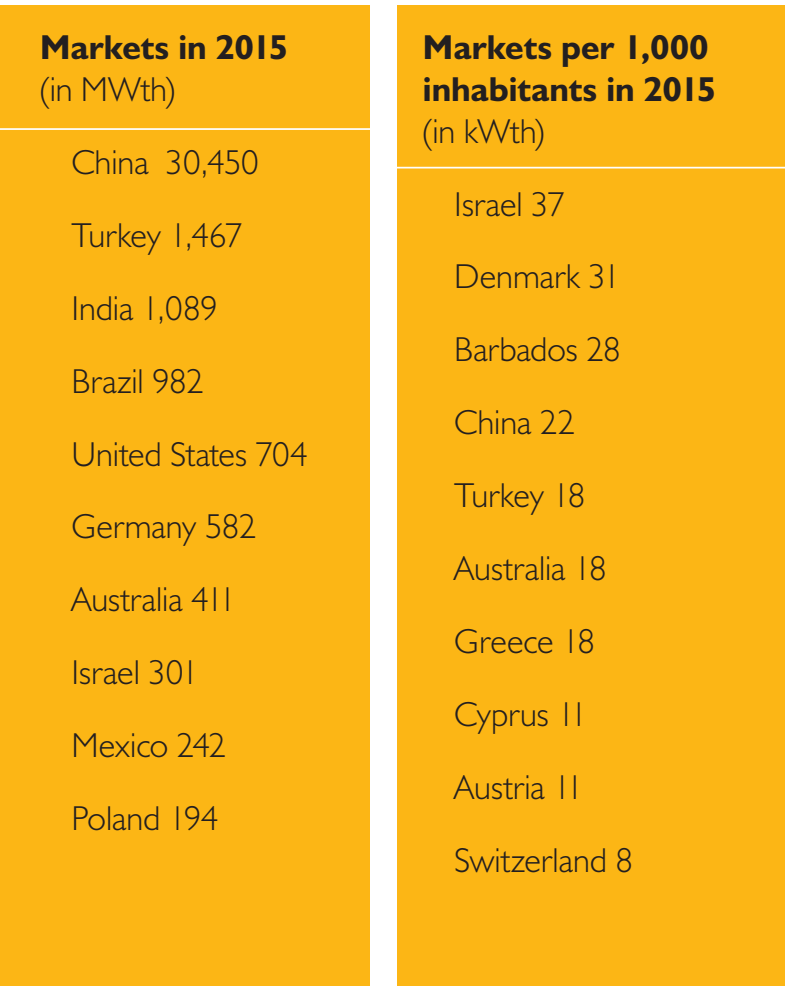




\section{Material and Component Development for Thermal Energy Storage: Objectives and Outlook}

There is a growing recognition that progress in clean energy needs to accelerate, especially in the building and energy storage disciplines. The Energy Technology Perspectives Report 2016 of the International Energy Agency states that heating and cooling for buildings is the elephant in the room.

\section{TACKLING THERMAL STORAGE}

The SHC Programme has a history of activities in this sector; beginning with SHC Task 32: Advanced Storage Concepts for Solar Thermal Systems in Low Energy Buildings, which brought together globally dispersed thermal energy storage (TES) research activities and initiated a combined effort on the characterization of phase change materials (PCMs) for heat storage. This work was accompanied by exchanging the first experiences in the technology development and performance simulation of concrete applications of PCM and thermo chemical material (TCM) heat and cold storage systems. The clear dependence of the TES system design on the storage material properties showed the need to encompass both research fields and led to the recognition of synergies with the expertise in the IEA Energy Conservation through Energy Storage Programme (IEA ECES). This work was followed by SHC Task 42: Compact Thermal Energy Storage, a joint activity with ECES Annex 24 and later Annex 29, and results were the intensified characterization and understanding of PCM materials and improved quality through courses and round robin tests. PCM and TCM studies on material to system demonstrator scale were covered in combined groups, and a growing recognition of their strongly diverting disciplines emerged. This work is now in its third phase, another joint activity SHC Task 58: Material and Component Development for Thermal Energy Storage/ECES Annex 33 , which is continuing to support this track of highly needed research and development, but this time in two individual technology lines, PCM and TCM, and incorporating development on the material and component levels.

\section{EXAMPLES FROM PREVIOUS AND ONGOING RESEARCH}

Progress in respect to real life applications is needed, especially for further material development, standardization of characterization techniques, material characterization and component development. Large discrepancies between material performance and system performance have led to the understanding that material characterization in light of system application is required for both novel and common materials.

\section{Sodium hydroxide}

An example of material characterization work for a common material is

TCM heat storage development based on aqueous sodium hydroxide. Sodium hydroxide, a very common chemical with a wide span of industrial application features a thorough characterization in its typical employment. The high affinity of sodium hydroxide to water, enabling a heat capacity of more than $400 \mathrm{kWh} / \mathrm{m} 3$, makes it a valid candidate for absorption heat storage. In the EU FP7 funded project COMTES this line of development was followed by implementing a classic falling film tube bundle heat and mass exchanger design shown in Figure I. Even though both the material and the components were common and well characterized, the performance in this application was found to be poor due to the novel operation conditions as heat storage. The conventional tube bundle heat and mass exchanger does not permit adequate exposure time to water vapor for sufficient absorbent concentration difference, and low absorbent flow leads to poor wetting of the tube bundle. Concrete characterization of sodium hydroxide under heat storage application is now underway in order to design novel, adequate heat and mass exchangers. 


\section{Zeolite}

Another development within the EU funded COMTES project is the development and testing of a seasonal solar thermal storage system based on solid adsorption of water vapor in zeolite I3XBF. The laboratory test system consisted of a solar thermal collector field, two vessels containing $700 \mathrm{~kg}$ zeolite each, an evaporator/condenser unit and a condensed water storage vessel. The cold source for evaporation/condensation was simulated by a computer-controlled cooling element. Figure 2 shows the schematics of the built demonstrator. Storage densities of the bulk material reached measurements over $180 \mathrm{kWh} / \mathrm{m} 3$, which is a record value for systems of this size in the built environment. Nevertheless, the evaporator performed well below expectations due to a lack of knowledge of the evaporative processes under low-pressure conditions. There is good news though, this has led to new research and development activities aimed at understanding and optimizing evaporators at low pressures and temperatures for the specific application.

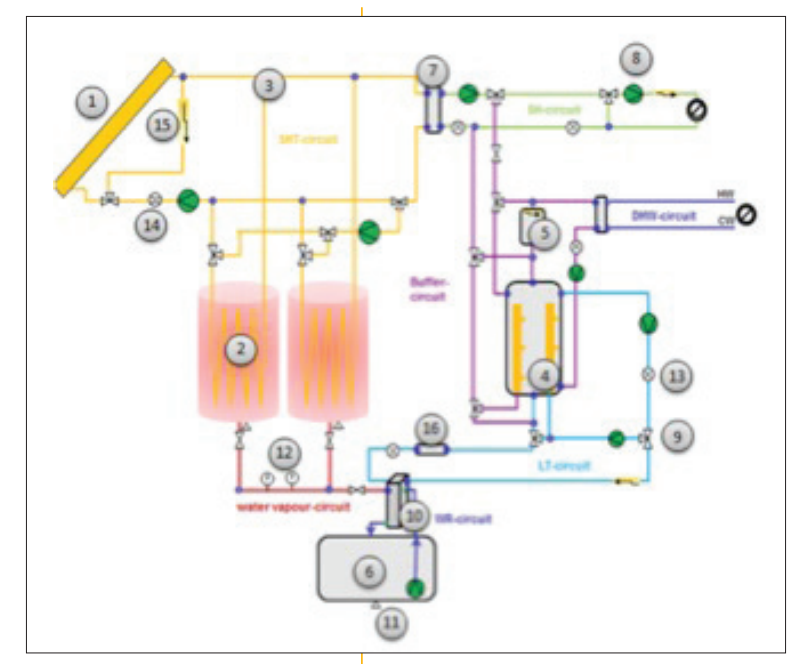

\section{Thermal Energy Storage (TES) system integration and application}

Effective integration and proper application of TES systems is vital for their success. This is often not a trivial task. The research project DISTRITES (Integration of thermal energy storage into district heating and cooling to increase the solar fraction and renewable energy resources 2015-2017, Spanish National Public Funds) deals with this work. Among others, the use of latent TES emulsions as heat storage in district heating and cooling is being studied. Depending on the location of the storage, thermal power and stored density requirements are determined in order to optimize system configuration and operation. This is an important activity and included in the new SHC Task 58/ECES Annex 33.

PCMs often require specific adaptation to their application in respect to temperature range and price. Most basic pure salt hydrate PCMs are known and characterized. Mixtures of two salt hydrates or a salt hydrate and a salt for optimized specific application are being investigated in the project "properPCM" (Property prediction and characterization of mixtures for the development of efficient phase change materials in relevant temperature ranges). In order to identify interesting compositions and to reduce the experimental effort, prediction models are applied to determine solid-liquid phase diagrams. For example, the solidliquid phase diagram of the system $\mathrm{LiBr}+\mathrm{LiNO} 3+\mathrm{H} 2 \mathrm{O}$ as shown in Figure 4 has been calculated using the modified BET model. The intersection of the boundary curves at the point $\mathrm{E}$ corresponds to a ternary eutectic. In order to verify the predicted phase diagrams, calorimetric measurements of such eutectic compositions and measurements of the solubility of ternary mixtures will be carried out.

Further in line with specific applications, the project SolSpaces from the Institute for Thermodynamics and Thermal Engineering at the University of Stuttgart is investigating a new heating concept for compact residential buildings. The project aims to cover 100\% of the space heating demand of an energy efficient building from solar thermal source.

The core element is a $4 \mathrm{~m}^{3}$ adsorption storage system, serving to cover seasonal supply and demand discrepancies. The demo system is installed in a compact research building for testing and demonstration.

Adsorption processes are well suited for long term energy storage due to the quasi loss free energy storage and the high energy storage density, compared to hot water tanks. However, adsorption materials, by nature of their high porosity, show very poor thermal conductivity leading to challenges in system design. In the SolSpaces project, a new approach was followed by subdividing the storage vessel into several segments, which resulted in improved operation at the cost of increased system volume. Advantageous component design is a critical element for heat storage systems.

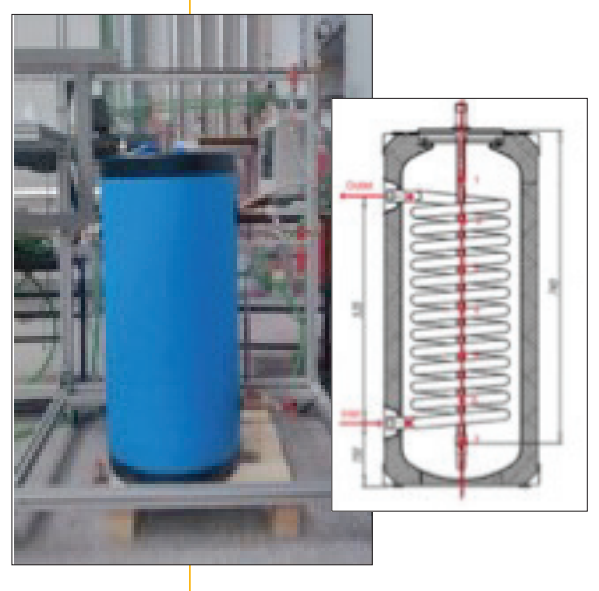

Figure 2. Schematic of the experimental seasonal solar thermal storage system based on solid adsorption of the COMTES project (development line A). The zeolite is contained in two vessels (2) and the complete system is under low pressure. Component 10 is the evaporator, which was found to have much lower performance than calculated.

$\Delta$ Figure 3. An example of a storage tank studied in the DISTRITES project. The tank is filled with various PCM emulsions. 
Scale-up effects are found in both PCM and TCM thermal energy storage developments. Nucleation for example, is a challenge encountered in PCMs. Materials showing super-cooling remain liquid below their phase change temperature thus permitting lossless heat storage. Nevertheless, exact behavior depends on operating conditions such as sample size, cooling rate, geometry, etc. There are many promising materials to be used for phase change thermal storage and a better understanding of both characterization schemes and specific characterization will enable optimal deployment. Results from the EU FP7 funded project SAM.SSA show that this is vital. In the SAM.SSA project molecular alloys based on sugar alcohols, so called MASA, with adjustable melting points where studied. The challenge of controlling and activating solidification was identified as a major bottleneck in most of the materials studied, hindering stable operation in specific applications.

\section{Storage design}

Storage design and operation greatly affects thermal performance, capacity, power, temperature, material degradation and corrosion. It follows that characterization is required at material and system level and must incorporate application specific conditions. Much work is yet required on the level of identification of important application parameters as well as definition of applicable testing procedures.

In the project "STAID", (Seasonal Thermochemical heAt storage In builDings), a solution for electrical peak load shaving for buildings is sought. The aim of the work is to develop and to characterize a zeolite thermal energy storage system able to shift building thermal related electrical load for electric grid stabilization on a daily basis. In this project, Zeolite $\mathrm{Na}-\mathrm{X}$ is used due to its lower price compared to zeolite $\mathrm{Na}-\mathrm{Y}$. The experimental results show that an open reactor design is feasible. In the dehydration or charging process, air at a temperature of $180^{\circ} \mathrm{C}$ is passed through the packed bed reactor, whereby water is removed. In the hydration or heat release process, air at a temperature of $20^{\circ} \mathrm{C}$ and a relative humidity of $70 \%$ is supplied to the zeolite, whereby heat is released due to the adsorption of water vapor on the zeolite. In a real life situation depending on climate and season, accessible humidity may differ strongly. This shows that specific application design is crucial for good performance.

\section{TASK ACTIVITIES}

The new joint SHC Task 58/ECES Annex 33: Material and Component Development for Thermal Energy Storage focuses on furthering the understanding and development of PCM and TCM materials, the development of measuring procedures for characterization and test methods for validating the performance of PCMs and TCMs, as well as the development of effective design approaches for specific components. This work is divided into PCM and TCM

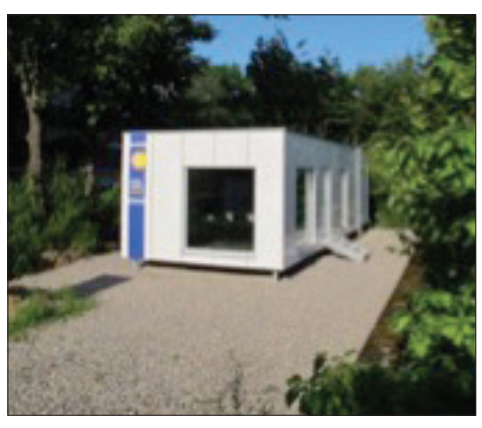
workstreams and four subtasks.

Subtask I: Energy Relevant Application for an Application-oriented Development of Improved Storage Materials features a cross-cutting endeavor involving both PCM and TCM workstreams. Within previous SHC Tasks, the influence of operation conditions given by the

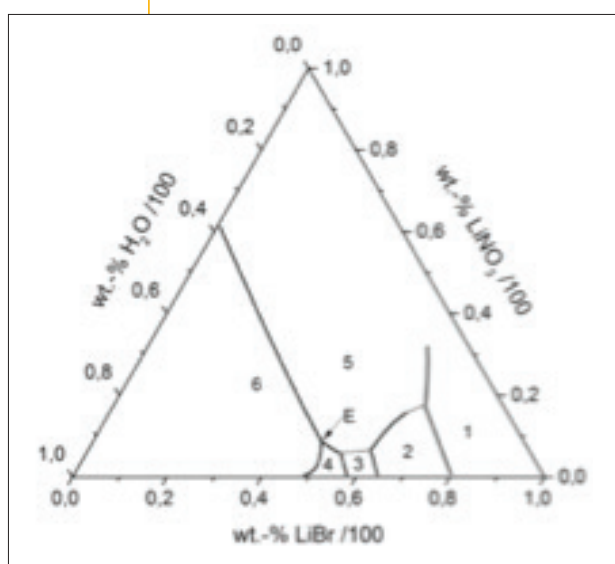

A Figure 4. Phase diagram of the system $\mathrm{LiBr}+\mathrm{LiNO3}+$ H2O; solid phases: $\mathrm{LiBr}(\mathrm{I})$, $\mathrm{LiBr} \cdot \mathrm{H} 2 \mathrm{O}$ (2), LiBr·2H2O (3), $\mathrm{LiBr} \cdot 3 \mathrm{H} 2 \mathrm{O}(4), \mathrm{LiNO3}(5)$, and LiNO3.3H2O (6); ternary eutectic $E$. A result from the properPCM project.

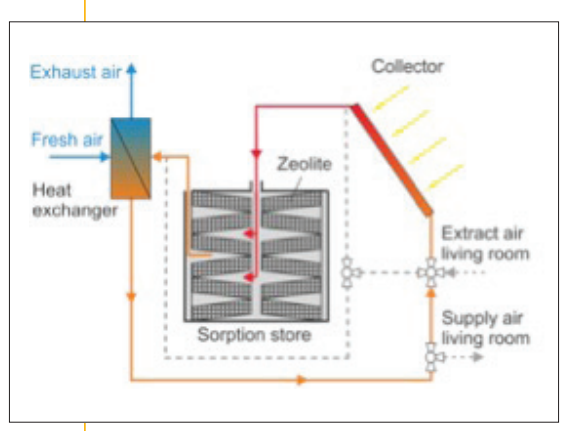

$\Delta$ Figure 5. Test building on the left and operation illustration on the right.
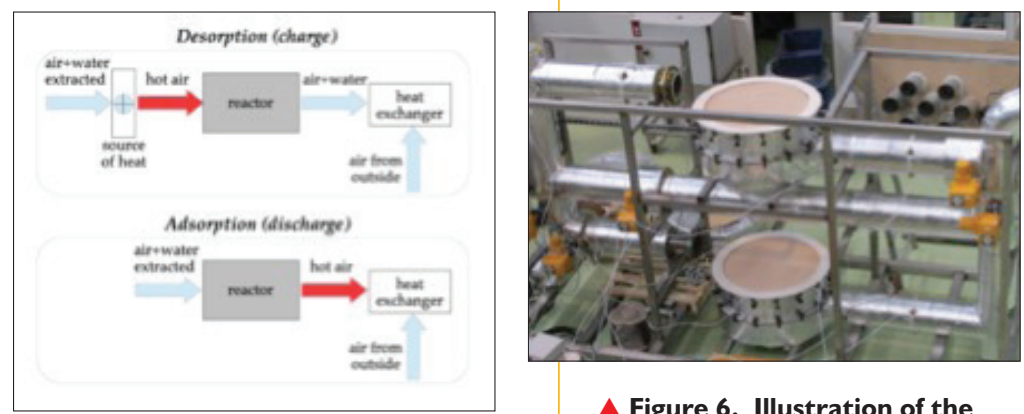

$\Delta$ Figure 6. Illustration of the STAID project operation scheme on the left and the demonstration system on the right. 
application was discussed, but no methodological approach has been initiated. It is the goal of this Subtask to reach an agreement on the operation conditions for a number of relevant applications. To this purpose a list of relevant thermal energy storage applications will be compiled including their operation parameters. This work will provide input to the other Subtasks, enable the definition of relevant key performance indicators (KPIs), give a basis for respective simulation work, and provide grounds for comparison and categorization of TES materials and systems. The Subtask takes up results from other ongoing or completed Annexes within the ECES Programme (e.g., Annex 30 for details from industrial applications and Annex 31 for input from the building sector), and looks into the work of SHC Task 44 on system classification performance assessment methods, as well as into the work of other IEA Technology Collaboration Programmes (TCPs).

\section{Subtask 2: Development and Characterization of Improved} Materials aims to develop and characterize TES materials. The work will be divided into the PCM and TCM workstreams. In the previous Task a material database was initiated for both PCMs and TCMs and will be continued, upgraded and expanded on the level of both material and quality in this Task. In the field of PCMs, blends, mixtures and composite materials show to be promising candidates. These require the adoption and definition of new appropriate characterization methods. Activities on TCMs include, development of new materials for sorption and chemical reaction and extends to the combinations of materials for application tuning. Critical parameters and characterization methods remain to be defined for repeatable material characterization. This will lead to the design of materials for specific applications as allocated in Subtask I in conjunction to component restrictions provided from Subtask 4.

\section{Subtask 3: Measuring Procedures and Testing under} Application Conditions covers testing of TES materials under application conditions. This can be understood as an up-scaling or intermediate step from Subtask 2 towards Subtask 4 and real life applications. The required testing procedures naturally differ substantially between PCMs and TCMs, thus this work is also separated into the two workstreams. Operation conditions of relevant applications, which have been identified in Subtask I, will be used for realistic performance testing. Storage capacity as well as cycle stability are the main parameters to be identified as well as corrosion in conjunction with the storage material. The performance of PCMs and TCMs on a system or demonstration scale storage unit is often different from the material behavior measured at micro or lab scale. In order to be aware of these differences and to be able to select a suitable material for a given application, effects that occur when going from micro to macro or lab to application scale have to be investigated. Thereby, the impacts of a different sample size and a possibly different purity (e.g., analytical or technical grade) have to be investigated. Test procedures to assess and quantify the up-scaling effects will be identified and elaborated.

\section{Subtask 4: Component Design for innovative TES Materials} furnishes this Task with a new focus on component development for newly developed materials. Improved performance parameters such as, system energy density, output temperature, thermal power, storage efficiency, stability and others strongly depends on the development of appropriate components such as the heat exchanger as well as the mass exchanger where applicable, the storage tanks, the system and operation strategy, etc. The design of the component is also highly important for any economic analysis of the storage system. For both workstreams, an inventory of known concepts will be established to support future system designs and detect bottlenecks and performance degradation.

The new Task consists of 4 I organizations from 13 mainly European countries. The Task began with a kick-off meeting in Lyon, France in April and will continue for 3 years with semi-annual meetings in partner countries.

\section{CONCLUSION}

Over the past 8 years, a large number of new developments in the field of materials, components and systems for compact thermal energy storage have been achieved, in part thanks to the good collaboration in previous IEA SHC/ECES joint work on this topic. With the experiences from these activities, SHC/ECES Task58/Annex33 will work on both phase change materials and thermochemical material technologies. For these technologies, new materials and material combinations will be developed, testing and characterization techniques will be developed or improved, and components will be designed and tested. With design conditions derived from a number of storage applications, the developments in the Task will be application driven wherever possible.

This article was contributed by Benjamin Fumey, Empa Swiss Federal Laboratories for Materials Science and Technology, Dübendorf, Switzerland, benjamin.fumey@empa.ch; Ana Lazaro, University of Zaragoza, Zaragoza, Spain, ana.lazaro@unizar.es; Wim van Helden, AEE - Institut für Nachhaltige Technologien, Gleisdorf, Austria,w.vanhelden@aee.at; Frédéric Kuznik, Institut National des Sciences Appliquées de Lyon, Villeurbanne Cedex, France, frederic.kuznik@insa-lyon.fr; Henner Kerskes, University of Stuttgart, Stuttgart, Germany, kerskes@itw.uni-stuttgart.de; and Christoph Rathgeber, ZAE Bayern, Garching, Germany, christoph.rathgeber@zae-bayern.de. For more information visit the SHC Task 58 webpage, or email the Task Operating Agents, Wim van Helden,w.vanhelden@aee.at or Andreas Hauer, hauer@muc.zae-bayern.de. 
COUNTRY HIGHLIGHT

United Kingdom
Innovation, integration

\section{and a new industrial}

strategy provide hope

Although new solar thermal deployment in the United Kingdom (UK) has decreased year on year since 2010, there are signals of a potential revival in the UK solar thermal market. Pursuit of the UK's carbon emission reduction targets in the 2020s is expected to lead to the introduction of new policies to stimulate significant uptake of low carbon heating and hot water for buildings; a substantial boost in support for innovation, a new industrial strategy that promises to deliver clean growth and the re-joining of the IEA Solar Heating and Cooling Programme in 2015, provide the solar thermal industry with a platform from which to work towards solar thermal making a significant contribution to low carbon heating and hot water in the UK.

\section{SOLAR THERMAL MARKET}

\section{Energy Projections}

The 2008 Climate Change Act established a legally binding target to reduce the UK's net greenhouse gas (GHG) emissions to $80 \%$ of 1990 levels by 2050. The Department for Business, Energy and Industrial Strategy (BEIS) projections (see Figure I) show that, given current Government policies, the UK is on target to achieve its emission reduction targets up to 2022 (the third carbon budget). Post-2022 (fourth and fifth carbon budgets), further Government measures are needed to achieve the required decarbonization targets.

For the UK, one of the biggest challenges is "decarbonizing the heating sector" (National Grid, Future Energy Scenarios 2016). Although emissions from the electricity supply sector have fallen significantly in recent years and are projected to fall further in the future, emissions from the domestic residential sector are projected to rise, with natural gas used for cooking and heating projected to rise by $17 \%$ (from 2016 to 2035) (BEIS Updated energy and emissions projections: 2016).

\section{Renewable Heat Incentive}

The main policy incentive for installing solar thermal is the Renewable Heat Incentive (RHI), which has been in operation since April 2014 and will end in 202I. For solar thermal, the RHI provides around 20 p of subsidy for every kWh of renewable heat for a household's hot water for a period of 7 years. For business, the non-domestic RHI tariff is around $10 \mathrm{p} / \mathrm{kWh}$ over a 20 -year period. Only solar thermal systems used for domestic hot water are eligible; this is not the case for biomass boilers or heat pumps where space heating installations are eligible for payments (www.ofgem.gov.uk).

Although solar thermal receives the highest $\mathrm{RHI}$ tariff, the number of installations in the UK has been falling in recent years (see Figure 2). In 2016, just over 10,000 m2 of solar water heating collectors were installed, down from 90,000 $\mathrm{m} 2$ at its peak in 2010 (Solar Trade Association, 2017).

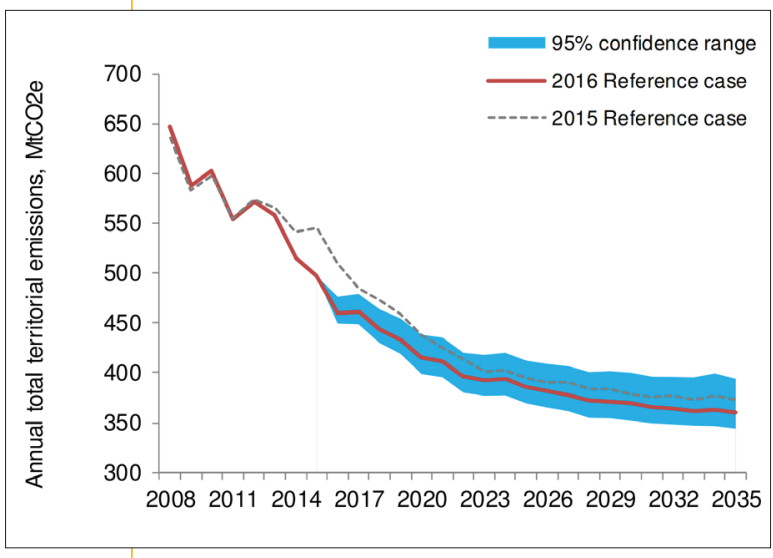

$\Delta$ Figure I. Actual and projected UK emissions. (BEIS, www.gov.uk)

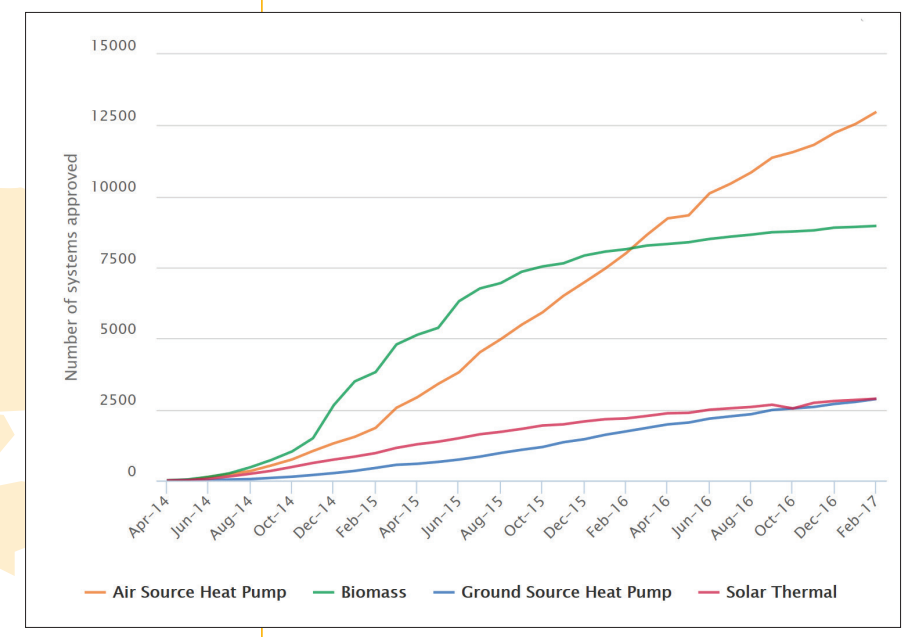




\section{SOLAR THERMAL INDUSTRY}

\section{Public Opinion}

Although the number of solar thermal installations per year is decreasing, public opinion of solar thermal, and renewable energy in general, is very positive in the UK. The BEIS Energy and Climate Change Public Attitudes Tracker (PAT), which has been tracking public option on energy related issues since March 2012, has shown consistently that 75 to $80 \%$ of the public support renewable energy (BEIS PAT Wave 20, www.gov.uk). Public awareness for solar thermal in particular is strong (highest among the renewable heat technologies), however, less than 15\% of those surveyed, and who were aware of renewable heat, are considering installing solar thermal in the near future. The main reasons for not installing solar thermal were the perception of high installation cost and survey respondents not owning their own property, but renting.

\section{Solar Thermal Water Heaters}

Despite the difficult market conditions, the UK has retained a strong manufacturing base that includes AES Solar, which has been manufacturing flat plate solar collectors in Scotland since 1979 (Figure 3), DiscreteHeat, Kingspan, Solar UK, and Viridian Solar. Since the introduction of the RHI in April 2014, 2,879 solar water heating systems have been approved (Feb 2017 figures, www.ofgem.gov.uk). Given the nature of the UK market, many of these systems are roofintegrated, such as shown in Figure 5, which are designed to replace roof tiles.

One of the challenges for solar thermal water heaters in the UK is

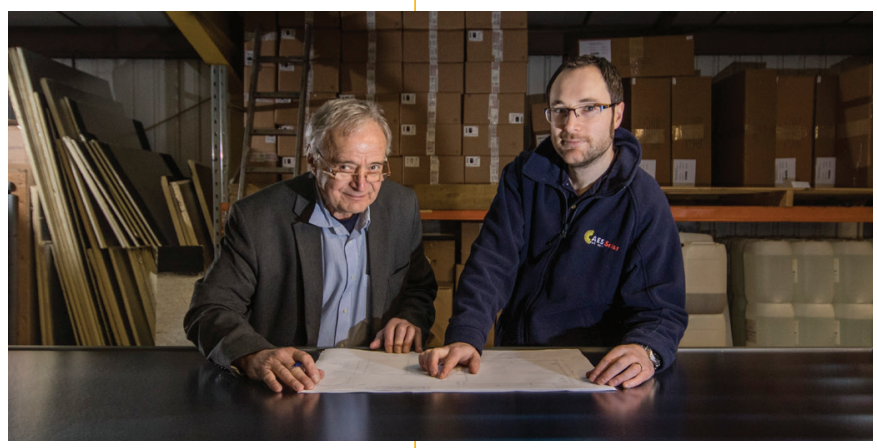
the popularity of wall hung instantaneous natural gas combination boilers (combi-boilers), which do not require a hot water tank. Given that new UK houses are the smallest in Western Europe (Royal Institute of British Architects, The Case for Space: the size of England's new homes), this can make installing a new hot water cylinder a challenge. Solar thermal systems with small hot water tanks that are designed to pre-heat the cold water supply for a combination boiler are available in the UK. Another challenge is the competition for roof space from the increased deployment of roof-mounted photovoltaics (PV). As a reaction to this, several UK companies offer PV power diverters, which will divert excess $\mathrm{PV}$ generation into a hot water tank immersion heater.

\section{Passive and Active Solar Thermal Air Heaters}

Passive solar air heating in the form of double-skin facades is well known to UK architects and has been in use since the 1960s. It was famously used in 196I at St. George's School, designed by architect Emslie Morgan, which operated for decades with only passive solar heat (Denzer 2013, The Solar House). Various forms of the double-skin facade are commonly found on high profile office buildings in major cities, for example, the Foster and Partners designed 30 St. Mary Axe (also known as The Gherkin) in London, which uses a double-skin face for passive solar heating in the winter.

More recently, active solar air heaters have become more common in the UK with several metal cladding companies offering solar air heaters as part of their product portfolio. Since their introduction to the UK market in 2005, over 12,000 m2 have been installed, with the largest being a $4,334 \mathrm{~m} 2$ collector installed on the Marks \& Spencer (M\&S) distribution center at Castle Donington (see Figure 4).

\section{SOLAR THERMAL INNOVATION}

\section{Industrial Strategy}

The UK Government recently set out a new industrial strategy (Figure 6) with the objective of improving "living standards and economic growth by increasing productivity and driving growth across the whole country." Part of this modern industrial strategy is to deliver "affordable energy and clean growth" and "secure the economic benefits of the transition to a low-carbon economy" 
(HM Government, Building our Industrial Strategy Green Paper, 2017).

To enable this, the UK Government is planning a major increase in research and development spending, with an additional $€ 2$ billion more per year funding by 2020-2I (Autumn Statement 2016, http://www.gov.uk). This new funding will be delivered through the Research Council's, Innovate UK and a new funding body UK Research and Innovation (UKRI).

\section{Solar Thermal and Heat Pumps}

A variety of work focusing on the integration of solar thermal technology and heat pumps is currently being undertaken in the UK. For example; Helios House in Bristol (see Figure 7) combines a roof-integrated 12.85 kWp PV array with a ground source heat pump and a compact thermal store (charged via a PV power diverter), E.ON is carrying out feasibility work with SK Solar, Star Renewable Energy and the University of Exeter for a district heating system which combines 2,000 m2 of solar thermal collectors with a high temperature ammonia heat pump and AES Solar is working on the EU Heat4Cool project, which is investigating the integration of solar thermal with adsorption heat pumps.

\section{New Member of IEA SHC}

After a short break, the UK has returned to the IEA SHC with significant solar thermal expertise and has much to contribute to current and future Tasks. In particular, specialists are working on building-integrated solar collectors, solar powered heat pumps (heating and cooling), high temperature collectors and compact thermal storage.

Several UK solar thermal experts are currently actively engaged with the IEA SHC. For example; Professor Andy Ford from London South Bank University is participating in Task 58 (Building Integrated Solar Envelope Systems for HVAC and Lighting), Philip Griffiths from the University of Ulster (Belfast) participated in the now completed Task 42 (Compact Thermal Energy Storage) and Naked Energy, a UK company working on an evacuated tube PVT collector, presented at the first definition meeting for the new Task on Application of PVT Collectors and New Solutions with the PVT Systems.

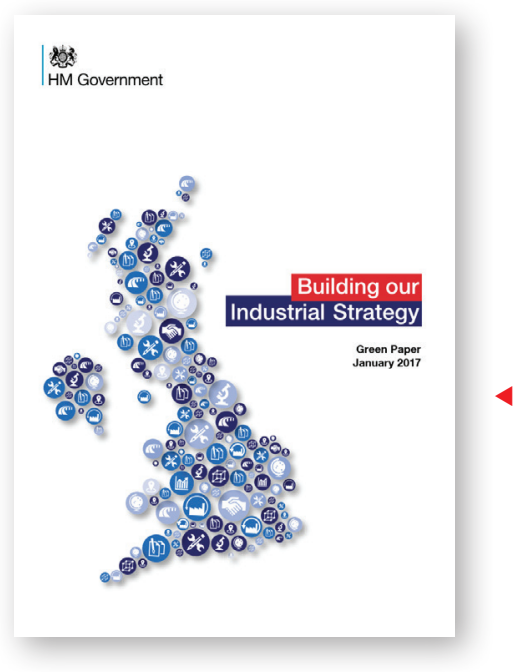

4 Figure 6. January 2017 green paper on a new industrial strategy for the UK. (www.gov.uk)

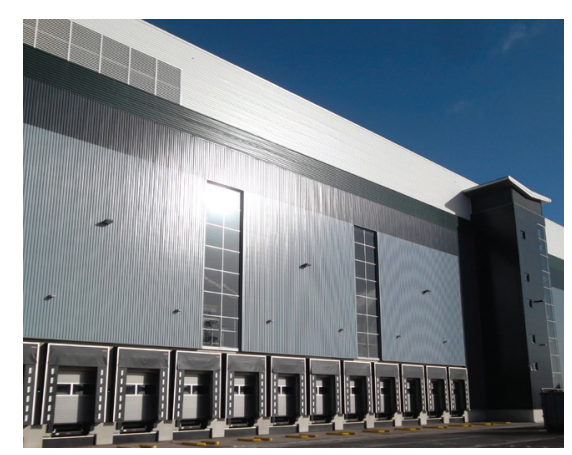

A Figure 4. In 2013 CA Group manufactured and installed one of the world's largest solar air heaters for a M\&S distribution center.

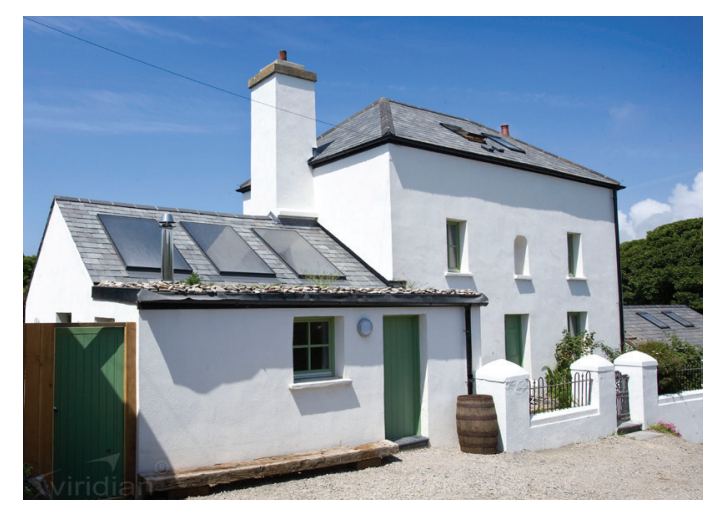

$\Delta$ Figure 5. Viridian Solar roof-integrated solar water heating system installed on a Welsh cottage with slate roof.

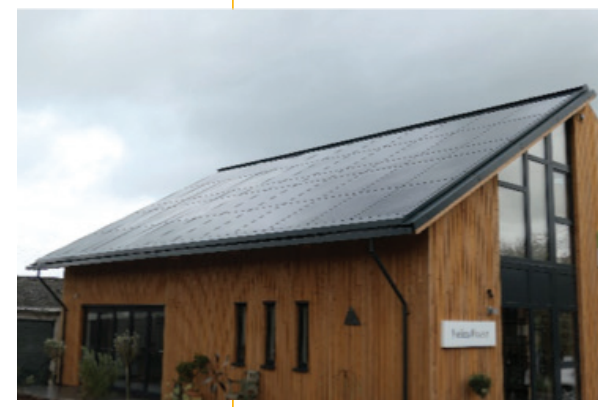

$\triangle$ Figure 7. Helios House combines a GB-Sol roof-integrated $\mathrm{PV}$ array with a Sunamp compact heat store and a Kensa ground-source heat pump.

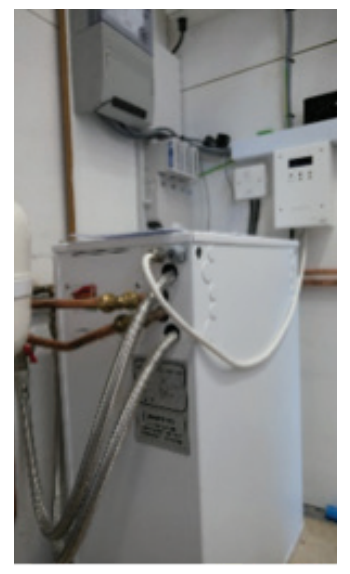




\section{Potential for Growth}

To meet its legally binding emission reduction targets, the UK must decarbonize its heating sector. Solar thermal could provide a useful contribution; however, the solar thermal industry must find ways to overcome the challenges that result from the popularity of combi-boilers, the dominance of biomass boilers within the RHI scheme and the competition for roof space from photovoltaics. To help solve these challenges, the UK solar thermal industry has the opportunity to actively engage with a new, significantly boosted, research and innovation funding programme. One possible solution, in which a number of research organizations in the UK are already actively exploring, is a combination of solar thermal, photovoltaics, compact/district storage and heat pumps.
This article was written by Dr. Richard Hall (drrichardhall@ energytransitions. Uk) who is the UK Alternative IEA SHC Executive Committee Member and specializes in the research and development of transpired solar collectors.

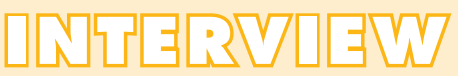

\section{Solar Resource Assessment and Forecasting}

\section{Interview with Dave Renné}

The IEA SHC Programme wrapped up its work on Solar Resource Assessment and Forecasting (Task 46), and has turned the management of its follow-on work to the IEA PVPS Technology Collaboration Programme. To learn first hand about the impact Task 46 has had in this field, we asked Dave Renné, the Task Operating Agent, a few questions.

\section{Why was this work needed?}

Dave Renné (Dave): As solar energy systems become larger, more complex, and more ubiquitous, the requirement for more and more accurate and complete information on the solar energy resource available to power these systems is required. This information must serve both the site planning and design of the systems, as well as the proper operation of these systems once they are deployed. Because of the high expenses associated with installing accurate groundbased measurements, more and more reliance on the use of satellite and other remote sensing data such as from satellite imagery is required to provide the necessary information.

\section{What were the benefits of doing this work thru the SHC Programme?}

Dave: The IEA SHC Task structure provides a very useful and effective platform to bring together global experts engaged in solar resource assessment R\&D, and to share their knowledge and to perform multi-national studies to improve our understanding of the solar resource as it pertains to solar system planning, design and operations. What is particularly valuable about this platform is that necessary rules and infrastructure are in place through the IEA to guide the scope of the joint research and to establish a work program with tangible timelines for completing key subtasks. The platform is also well recognized by the renewable energy community, thus establishing a high degree of credibility and reliability in the outcomes and publications of the joint activities carried out in the Task.

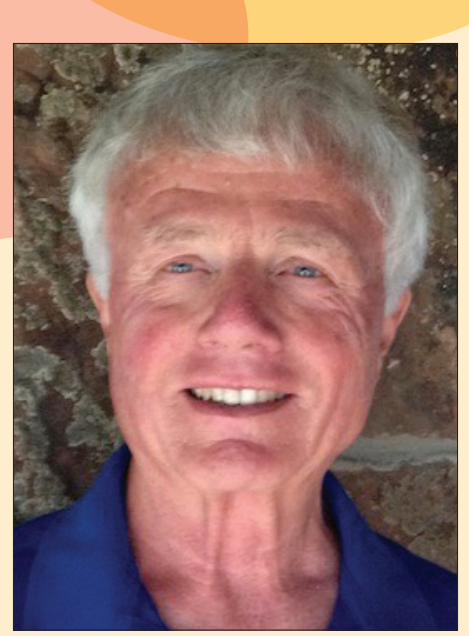

What, if any, result(s) surprised you?

Dave: One key surprising result is the accuracy to which the solar resource can be estimated using satellite-based remote sensing information. Although work on these methods has been underway for several decades, this Task has shown that the current satellite-based techniques provide accuracies approaching (and in a few cases exceeding) the accuracy available through high-quality ground-based measurements. A second surprising outcome is the extent 
to which lower-cost Rotating Shadowband Radiometer can provide measurement accuracy and reliability when compared with the more expensive thermopile-based measurement procedures. A third surprising result is the understanding of the importance that the circumsolar radiation emanating from the sun can have on the direct normal irradiance available to concentrating solar systems.

\section{What is the most important deliverable(s) of the Task and why?}

Dave: The most important deliverable, which came out as an interim deliverable in 2013 and will soon be issued as a final deliverable, is the "Best Practices Handbook for the Development and Use of Solar Resource Data". This manual, developed by the U.S. National Renewable Energy Laboratory, captures the key outcomes of the Task work undertaken by its many participants. Other key deliverables include: I) a best practices handbook on solar resource measurements using Rotating Shadowband Radiometers, 2) a Task report on data adaptation methods (merging long-term satellite-derived with shorterterm ground data), 3) a summary of studies benchmarking solar resource forecasts with ground-based measurements and system outputs, and 4) a journal publication documenting the importance of the circumsolar effect on direct normal irradiance measurements and the significance of this effect on estimating the performance of concentrating solar collectors.

All of these deliverables are important in that they give end-user and project financers a much clearer understanding of project risk based on the current knowledge available for depicting the solar resource available to solar technologies.

\section{Do you have a success story about a Task deliverable being used by an end-user/industry?}

Dave: We are aware that the Interim Task Deliverable "Best Practices Handbook for the Development and Use of Solar Resource Data" has been widely used by industry as a definitive guide for acquiring and applying solar resource information for supporting solar system design and operations.

\section{How has your Task work supported capacity and skill building?}

Dave: A long list of conference presentations, institutional publications, books and book chapters, and peerreviewed journal papers has been developed under this Task. In addition key Task participants organized and presented several webinars and conference workshops on the work and outcomes of the Task. Many of the Task Participants are engaged in university teaching activities, and many also serve as technical reviewers for peer-reviewed journals and book publications.

\section{What is the current status of the technology?}

Dave: Currently we are able to provide solar resource information derived both from ground measurements as well as through satellite remote sensing and numerical weather prediction techniques with quantifiable levels of uncertainty. Techniques, also with known levels of uncertainty, to predict the solar resource at a given location or throughout a region over various future time horizons (such as I-hour ahead, I- to 6-hour ahead, and I- to 7-day ahead) are also available. Having quantifiable statistical measures of data uncertainty is valuable to investors in determining the "bankability" of proposed and operational solar system installations at any location. A useful summary of the state-of-the-art solar resource technology is summarized in the Task's interim and final deliverables, "Best Practices Handbook for the Development and Use of Solar Resource Data", produced by the U.S. National Renewable Energy Laboratory.

\section{What is the future of the technology - new developments, market, policies needed?}

Dave: The demands for and use of high quality, reliable solar resource data, both for evaluating how systems might perform in specific locations and also for how best to optimize the operation of systems using forecast data, continues to grow. Thus further efforts on improving the accuracy and reliability of these data, especially for solar resource forecasts, and improving the cost-effectiveness of acquiring these data without sacrificing reliability or precision, will continue. As more and more variable solar resources are integrated into energy systems, the ability to optimize how these systems can be utilized in the overall energy supply network will become increasingly important. Without good knowledge of the variable characteristics of the solar resource, both in time and in space, and especially for predicting this variability over future time horizons, the amount of solar that can be integrated into energy delivery systems will be limited, thereby limiting the potential market for these systems. So, continuing with this Task work is essential for ensuring growing solar technology markets around the world.

\section{Will we see more work in this area in the SHC Programme?}

Dave: This Task will continue as Task 16 under the IEA PVPS Programme for three more years, beginning in July 2017, and will maintain a formal level of collaboration with both IEA SHC and IEA SolarPACES. Some SHC member countries (who are not members of PVPS) will be able to continue participating in Task 16 through this collaborative arrangement. Most of the participants involved in SHC Task 46 will continue under the new PVPS Task 16.

\section{Did the Task work on/support any standards?}

Dave: The Task work did not result specifically in new standards, although it has reported on standards that apply for measurement best practices. The Task work also reported on other best practice methodologies, such as I) merging highquality ground-based measurements with reliable long-term satellite-derived estimates to produce bankable long-term solar resource data sets, 2) incorporating the best information available for characterizing the influence of aerosols and dust on the satellite-based solar resource estimates, and 3) identifying the key statistical metrics that should be applied for benchmarking satellite-derived solar resource data and solar forecasting techniques against ground-based measurements and actual system outputs.

Reports and other information on SHC Task 46 can be found at http://task46.iea-shc.org/. 

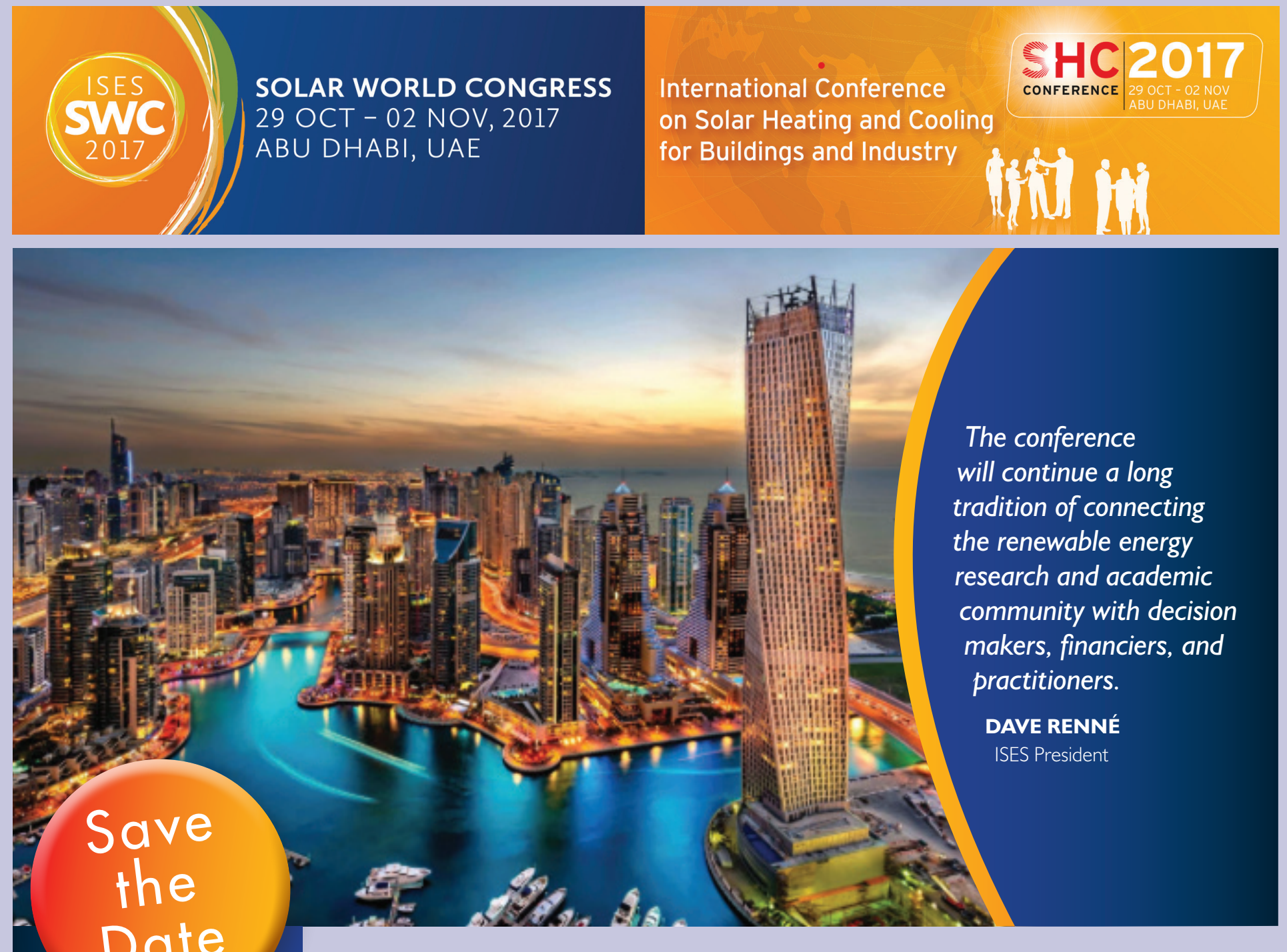

SHC 2017 and SWC 2017 join forces to offer the "must attend" solar event of 2017.

\section{Registration}

\section{opens June 26th!}

Our joint conference is certain to reach a wide network of participants interested in exploring technical, industrial and policy synergies relevant to renewable energy deployment.

\section{KEN GUTHRIE}

IEA SHC Chairman
We hope you'll join us and the conference host, Masdar Institute of Science and Technology, in Abu Dhabi this October 29 - November 2.

By joining these two conferences you will find in one place the most up-to-date information on renewable energy technology trends and breakthroughs, global and regional policies, and market opportunities.

The International Conference on Solar Heating and Cooling for Buildings and Industry, SHC 2017, will bring together the latest developments in solar heating and cooling and highlight market successes. SHC 2017 is sure to inspire you as you participate in the conference sessions and discussions and learn firsthand about the developments in the Middle East. It is the goal of SHC 2017 to have you leave ready to help deploy solar thermal technologies to become an increasingly significant contributor to a sustainable and renewable energy future.

The ISES Solar World Congress, SWC 2017, will address the key ingredients of the renewable energy transformation: technology innovation, financial opportunities, policy developments, as well as community and grass-roots actions, case studies and best practices that already are leading towards achieving a 100\% renewable energy system in cities and regions. Nevertheless, many challenges remain, and the ISES Solar World Congress 2017 will bring to the forefront a dialogue among diverse experts to discuss and formulate actions to meet these challenges. 


\section{Solar Thermal Trends}

With 2017 underway, it's important to stop for a moment and think about where solar thermal is headed in the short-term and how current work can support or be adjusted to keep pace with technological advances. Several SHC Task Operating Agents have weighed in on trends in their areas of expertise.

\section{Solar Cooling}

- MENA region. In the MENA region there is growing interest in renewable energy and energy efficiency in buildings, which will create ideal conditions for developing adapted solar cooling solutions. This will be especially true for devices that are adapted for harsh and dry climatic conditions.

\section{- Cost competitive solar thermal} cooling. The huge pressure coming from self-consumption photovoltaic heating and cooling solutions will make solar thermal cooling cost competitive. In the small power range, there is strong competition and solar thermal cooling costs are going down significantly.

- Pairing with DHW. There is a very good complement between cooling and domestic hot water (DHW) when using solar thermal in Europe. The design of the solar thermal cooling system can be based on an entire year of regular and significant domestic hot water needs with the surplus solar energy in the summer used entirely for cooling.

\section{Solar Thermal System Costs}

\section{- Bridging the gap between} research/industry and actual users.

R\&D working to change its "ivory tower" image (i.e., away from the people) and actually challenge what the energy market has in store for us. Researchers and associated industries need to reach out to users and service providers close to them (e.g., installers of solar thermal systems, energy consultants, architects, planners, etc.) and look for fruitful exchanges. Challenges "from the field" should be the center of the work done.
- Reducing costs. Ways to reduce costs are being pursued on the material and component levels, but should be pursued in every step of the value chain. One approach is to design standardized systems with standardized equipment and control systems for easy and quick installation.

- Compact heating systems. The combination of solar thermal components and heat pumps/electric heaters is replacing tradition heating systems.

- Transparency of costs. Innovative installation companies and marketing concepts will continue to show the true costs of solar thermal applications and systems.

- Telemonitoring. Developing solutions that allow digital monitoring of installations via the internet. By using these so called "telemonitoring" solutions companies can avoid unnecessary maintenance visits and only need to act when performance is actually decreasing (or any other failure mode is detected). This saves costs and improves the quality of their products and service.

\section{Large SHC Systems in DHC Networks}

- Online surveillance. Online network surveillance is the monitoring of solar field activities, its data storage, and its transfer.

Surveillance allows installers and operators to maintain field control, recognize and monitor threats, and prevent and investigate critical performance activities. Still, the ability to monitor field activities, whole system performance and district network integration is in its infancy.
- Simulation modeling. Developing and validating detailed simulation models of a solar heating system to anticipate operational performance. Modeling further assists system designers to assess the factors most relevant for designing large solar thermal systems. Modeling can also be used to investigate the behavior of the plant under different conditions and suggest possible improvements. Specific examples are the integration of superordinate control strategies (load management) for hybrid energy systems, detailed dynamic flow and heat transfer modeling of solar collector fields, and hydraulic network simulations.

\section{- Business cases for investments.}

Business cases on large-scale district heating networks can give a boost to new installations and the integration of solar thermal plants. Compelling solar thermal project cases will capture both the quantifiable and non-quantifiable characteristics to attract promising project investors.

\section{Compact Thermal Energy Storage}

- Thermochemical materials. The use of composites of porous materials and salt hydrates, and for higher temperatures, metal hydroxide-oxide reactions are working to improve thermochemical materials.

\section{- Component development and} testing. The targeted development and testing of critical components (e.g., heat exchangers, thermal reactors, and evaporators) will continue.

- Integration of thermal energy storages. Increased attention is being 
given to the integration of thermal energy storages in flexible grids and in e-mobility (electric vehicles, trains, etc).

\section{PV/Thermal Systems}

- Growing market. The market for PVT collectors is continuing to grow bolstered by the fact that PVT collectors optimize the available space on rooftops.

\section{- Increasing acceptance.}

Homeowners and builders are relying more and more on PVT systems for heating, cooling and delivering electricity to the building for self-consumption as an energy solution.
- Flexibility of technology. PVT collectors operate well in combination with heat pumps and are a premium source of energy for the evaporator during heating conditions, which gives them an important advantage.

- Energy output. PVT solutions drastically increase the energy yield of every $\mathrm{m} 2$ of collector or rooftop.

\section{Building Integrated Solar} Envelope Systems for HVAC and Lighting

- Building envelope. Integration of energy control approaches in buildings is a major challenge. The envelope is becoming an active and/or adaptive skin that interacts with the external environment and strongly influences the building energy performance and indoor comfort.

- Envelope integrated solutions.

Research and industry are developing envelope integrated solutions to harvest useful solar energy and/or control the solar gains into buildings.

- Market development. Reliability, duration, standardization and clear regulatory frameworks are key for the development of the market.

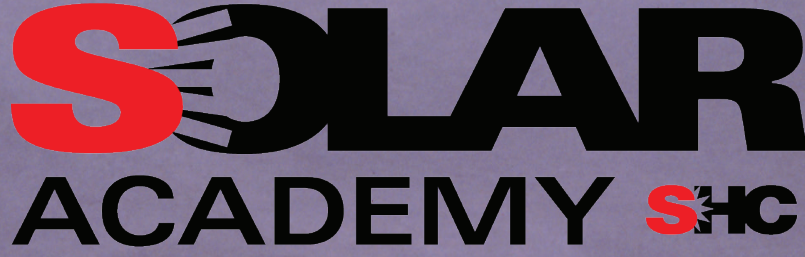

FOR HEATING \& COOLING IN BUILDINGS \& INDUSTRY
The SHC Solar Academy is the latest effort by the IEA SHC Programme to share it's work and support R\&D and implementation of solar heating and cooling projects worldwide. We hope that you will take advantage of one or more of the Academy's activities.

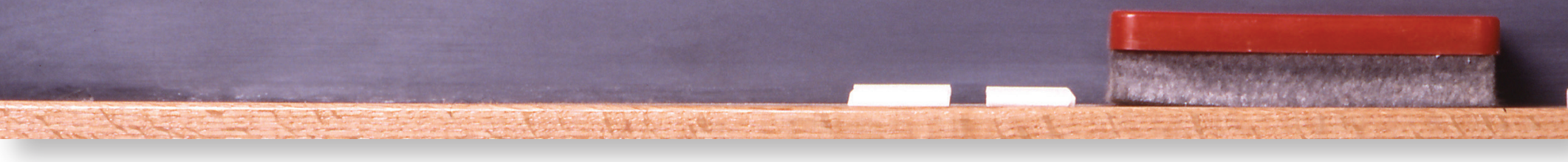

Webinars by IEA SHC experts on specific results and tools are being hosted by ISES.

\section{Webinar}

Advanced Lighting Solutions for Retrofitting Buildings held on March 2 Ist. If you missed it you can watch now click here.

\section{Webinar}

Solar Heat for Industrial Processes, join us on July 6 at 1:00-2:30 GMT. To register click here.

\section{Webinar}

Solar Energy in Urban Planning, join us on September 13 at 10:00- 1 1:30 GMT. To register click here.
Videos highlighting our work and other relevant issues. The first video package (I I videos) showcases presentations from Qatar's Green Expo held November 2016 in Doha. The speakers discuss our current projects and how IEA SHC is supporting solar thermal in the MENA region.

National Days held in conjunction with IEA SHC meetings are country specific events for the exchange of information between national experts and IEA SHC experts.

Onsite training offered by IEA SHC experts to IEA SHC members. 


\section{New Take on Solar Water Heater Micro Systems}

Energy supply in emerging markets and developing countries simply doesn't meet the actual needs of the people. When it comes to rural areas, in most villages electricity and hot water is not affordable. The majority of hot water is produced using the heat of burned resources like bushes and waste (e.g., plastic or cow dung). These substances are harmful to health, highly inefficient and damaging to the climate. Another very important fact is that many people have no access to even the lowest sanitary standards that would be provided by access to hot water service on a regular basis. Furthermore, there is a lack of electricity for lighting in houses in the evening. In many households, where paraffin or gas lamps are not being used, children are not able to do their homework and others are not able to do simple tasks within the home.

To address these issues, Sunlumo Technology has developed an affordable, decentralized micro energy supply system for small villages and rural areas to provide families with hot water and basic means of electricity. The system was designed using polymer materials, which is the key technology to maximize benefits and reduce costs. In addition, the combination of different technologies, including personal mobile devices, leads to a new approach to further reduce costs and boost system practicability.

This innovation is a very direct domestic hot water system, bottom-up made exclusively with polymer materials. Using this solar water heater technology, it is now possible to reduce energy costs sharply. Such a solar hot water system consists of one or more solar collectors, a pumping group, the connecting pipes, and a software control. To make it a complete micro energy supply system, the hot water system is enhanced by a photovoltaics module for power supply and system independence, also for off-grid systems.

\section{"The system was designed using polymer materials, which is the key technology to maximize benefits and reduce costs."}

The included photovoltaics module not only delivers the electric energy to run the pump for the solar water heater system, it also allows fulfillment of basic demands for lighting and mobile phone charging. For instance, one small off-grid system is able to provide light in the evening hours and enough energy to power a personal computer during the day.

The hot water system delivers water with temperatures up to $80^{\circ} \mathrm{C}$, which is essential for personal health and hygiene and also for comfort and wellbeing. The system is designed as a pumped system. This not only allows for the separate installation of the water tank, but more importantly, the use of existing resources like used oil barrels, canisters or jars as the hot water storages. Conventional solar hot water systems include a pre-made storage tank, which complicates logistics and increases the overall system costs. Having the opportunity to use existing on-site containers allows for flexibility, such as arranging the storage inside houses and filling the storage manually.

The whole system is designed for low complexity, practicability and usability and this is very important because of the limited technical knowledge of those operating the systems. 
Solar Water Heater from page 16

To assist with a system's setup and installation, users can rely on an illustrated operator's guide that is accessible through a mobile phone. Near field communication chips inside the solar system components are used to register and setup the solar system components correctly. Essentially the mobile phone is the connecting element between the user, a web based server, and the micro energy supply system.

This solution was not chosen to come up with a new trend in the technology market or to be overly future-oriented, but rather to follow the reality of daily life, which is that even in developing countries more smartphones are sold than conventional mobile phones. The smartphone is as much the swiss army tool in developing countries as it is in wealthier countries; and relying on this device is directly linked to user benefits. By using what people already have, it is possible to substitute the otherwise necessary system hardware and thus lower the price.

To further reduce initial acquisition costs, a major barrier for renewable energy systems, Sunlumo Technology developed a " pay-per-heat » business model. This concept, called PAYOUSE, removes that barrier by providing users with the necessary technology via an accessible renting model. In doing so, people still have instant access to the desired energy, but without having to pay for the complete equipment upfront. Instead, users pay a daily fee for renting the technology until the system is paid off. The payment system PAYOUSE is designed in a way that is just as simple and accessible as the solar system: Users can pay their fees by mobile phone calls or by redeeming codes from scratchcards sold locally just like mobile phone prepaid code cards.

Once a user has a sufficient balance on his account, he can activate his micro energy supply system and completely control the system using the easy to understand mobile phone app. With the app, users can manage and monitor the hot water system as well as the photovoltaics power source and can receive energy supply forecasts based on local weather predictions. The app is directly linked to the PAYOUSE payment system and allows switching between individual accounts on a daily basis for families or local communities to share an energy supply system and to distribute its costs in the most simple manner.

The mobile phone is also the interface of choice to connect with user communities. A planned education network for renewable energy will help people dealing with energy matters and teach and train users how to maintain the micro energy supply systems in case of failure.

Ultimately, this is the first easy and cheap solar energy supply system for both domestic hot water and electric energy that can be run without energy from the grid. Its unique characteristic of combining the minimal system complexity with on-site resources, such as existing storage tanks and personal mobile devices to manage the system, allows for the highest flexibility and lowest pricing. Additionally, the remaining system costs can easily be paid off with the associated PAYOUSE pay-per-heat renting model. Paired with the planned educational program, which will raise awareness and train people in the field of renewable energy, this makes for a great potential of progress in the long-term strategy for a renewable energy supply in emerging markets and developing countries. Pilot tests are now underway at Sunlumo and at AIT (Austrian Institute of Technology).

This article was contributed by Robert Buchinger and Max Wesle of Sunlumo Technology and participants in SHC Task 54: Cost Reduction of Solar Thermal Systems, robert.buchinger@ sunlumo.at, max.wesle@sunlumo.at 


\section{Levelized cost of heat calculations key for reducing the price of ST applications}

\section{T^ K 54}

SHC Task 54 on Price Reduction of Solar Thermal Systems aims to identify pathways to reduce the end-users' heating costs from their solar thermal systems. To do this, it is necessary to define an indicator to compare different system designs and technological solutions with one another.

The levelized cost of heat $(\mathrm{LCOH})$ was selected because it takes into consideration all costs over the lifetime of a system. Additionally, the concept is widely used in the electric power sector under the name, levelized cost of electricity (LCOE), thus facilitating its visibility and use in the solar thermal sector.

The calculation method developed within SHC Task 54 builds on the work of the EU funded FRoNT project', which laid the foundation for the application of the LCOH to any heating technology. Recent IEA SHC publications, for example the 2016 Solar Heat Worldwide report ${ }^{2}$ and the technical report, " $\mathrm{Cl}$ : Classification and benchmarking of solar thermal systems in urban environments" from SHC Task 52 on Solar Energy and Energy Economics in Urban Environments ${ }^{3}$ have included the notion of levelized cost of heat. The $\mathrm{LCOH}$ calculation results depend strongly on the considered assumptions. Therefore, SHC Task 54 proposed a more detailed methodology for the comparison between different solar thermal projects at different locations and even with fossil heating systems.

This method was tested on reference systems in single-family houses in Germany with current price data. As expected, the cost of heat is at the moment still higher in systems that include a solar thermal system compared to systems running only on fossil fuels, but increasing fossil fuel prices would quickly change this picture. As part of the work of SHC Task 54, participating experts will propose pathways to reduce the costs of solar thermal systems that will be verified by the comparison of the $\mathrm{LCOH}$. Figure I shows the sensitivity of the $\mathrm{LCOH}$ on 4 parameters (lifetime, saved energy, maintenance costs and initial investment). Significant cost reductions can be reached by different measures. The example in Figure I shows an overall cost reduction of 33\% for a lifetime and a saved energy increase of $20 \%$ while initial investment and maintenance costs are reduced by $10 \%$, each.

This article was contributed by Yoann Louvet, University of Kassel, yoann.louvet@uni-kassel.de. Detailed information about the calculation method can be found at http://task54.iea-shc.org/ info-sheets.

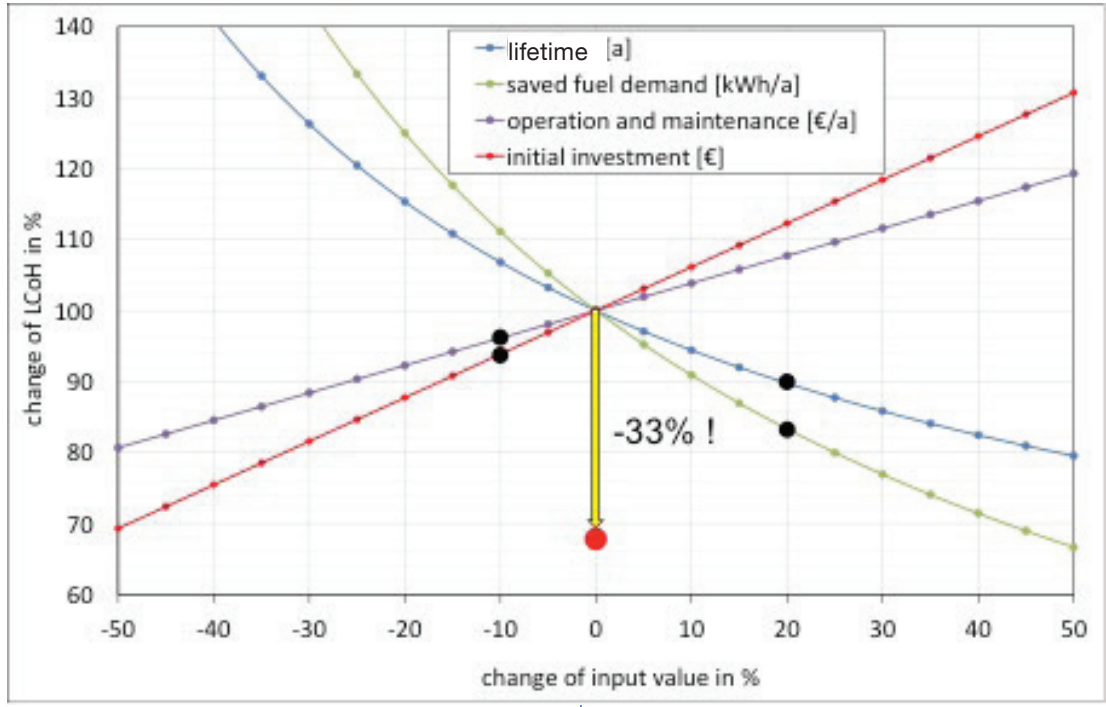

$\Delta$ Figure I: Sensitivity analysis of the LCOH with respect to lifetime, saved energy, maintenance costs, and initial investment.
Where:

$I_{0}$ : initial investment in $€$

$T R$ : corporate tax rate in $\%$

$E_{t}$ : saved final energy (year $\left.\mathrm{t}\right)$ in $\mathrm{kWh}$

$r$ : discount rate in \%

$T$ : period of analysis in year
$\Delta$ The LCOH for solar thermal applications can be derived from this formula.

Figure I and the corresponding calculation was contributed by Stephan Fischer, ITW/ TZS University of Stuttgart, fischer@unistuttgart.de

References

' http://www.front-rhc.eu/

${ }^{2}$ http://www.iea-shc.org/solar-heat-worldwide ${ }^{3}$ http://task52.iea-shc.org/publications 


\section{SHC Book Series}

\section{Two New Books Hit the Shelves}

Solution Sets for Net Zero Energy Buildings is the newest addition and 4th book in the SHC book series published by Wiley / Ernst \& Sohn.

"Net Zero-Energy Buildings have been the object of numerous studies in recent years as various countries have set this performance level as a long-term goal of their energy policies. This book presents a unique study of 30 NZEBs that have been constructed and have had their performance measured for at least 12 months. The study is based upon the work done in SHC Task 40/EBC Annex 52: Towards Net Zero Energy Solar Buildings.

It is the first book to evaluate building strategies in houses, educational buildings and offices that have been demonstrated to work in practice. It examines how the design challenges of climate and building type have been addressed, and to what extent the various design approaches have been successful.

The book presents convincing evidence that a careful re-thinking of conventional design norms can achieve a far greater performance benefit than is normally feasible. It identifies "solution sets" that work at the whole building level and at the individual building design challenge level for each climate and building type. In doing so, the book provides guidance as to how to improve the design by learning from these cases.

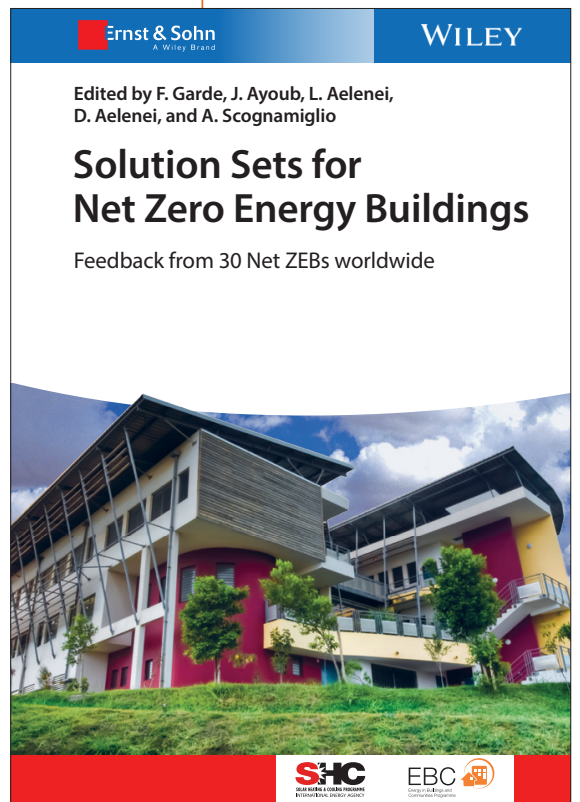

Unusual for a book of this type is that it has examples of buildings in what are conventionally labeled "hot" and "cold" climates. A simple process is proposed for the reader to commission the analysis of their own climate to assess not only the conventional measure of how hot or cold or humid it is, but also to assess its suitability to support other NZEB technical challenge solutions sets such as Daylight or Natural Ventilation or comfort based climate conditioning."

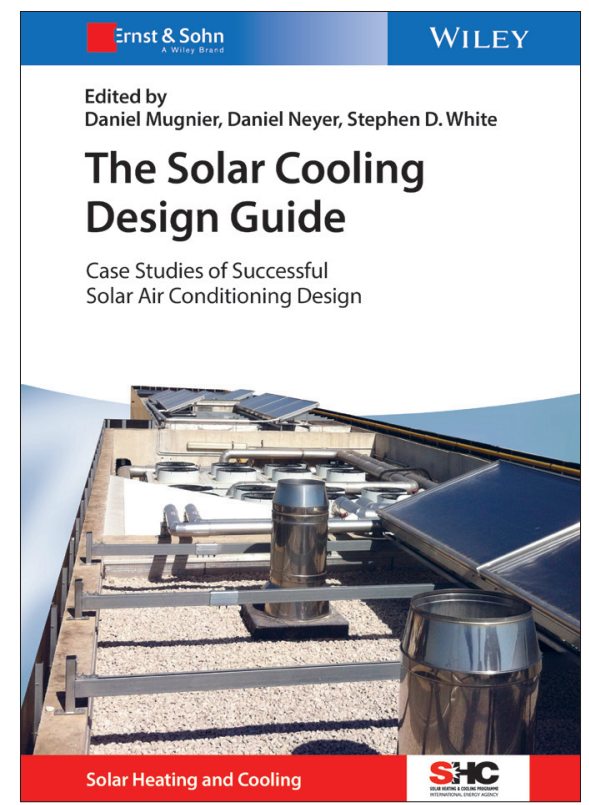

Order your print or e-book copy now:

www.wiley.com/WileyCDA/WileyTitle/productCd343360469X.html

www.ernst-und-sohn.de/en/solution-sets-for-net-zeroenergy-buildings

The Solar Cooling Design Guide will be published September 20 17. This book is a compendium of case studies of successful solar air conditioning designs with over 100 illustrations in its 132 pages. Pre-order your print or e-book copy now so you're ready when it's published in November 2017.

www.ernst-und-sohn.de/the-solar-cooling-design-guide 
The Solar Heating and Cooling Programme is not only making strides in R\&D, but also impacting the building sector. This section of the newsletter highlights solar technologies that have been developed or conceptualized in a SHC Task and are now being commercially manufactured, marketed or used.

\section{Innovators of the Year - Maria Cristina Munari Probst \& Christian Roecker}

SHC Task 5I: Solar Energy in Urban Planning experts Maria Cristina Munari Probst and Christian Roecker of Solar Energy and Building Physics Laboratory of the Federal Institute of Technology Lausanne (LESO/EPFL) received the Swedish Innovator of the Year award for their innovative assessment tool, LESO-QSV (QSV refers to Quality-Site-Visibility).

LESO-QSV is based on the concept of architectural "criticity" in urban areas. Under this concept, the acceptability of solar collectors is assessed against the sensitivity of the site and the visibility of the collectors in urban areas. This easy-to-use method makes it possible for municipal authorities in charge of planning and approving solar installations to take local architectural constraints, such as historical districts, into account when analyzing where to install solar panels on existing buildings.

The methodology matches three levels of visibility with three levels of sensitivity to define nine "criticity" situations for which different integration quality level requirements can be set. Before this tool, solar integration was primarily left to personal taste. Now with this criteria-based decision making tool, it is possible to objectivize quality evaluations.

The method is part of the tools used in Task 5 I's case studies work that will soon be published online in the report, "Illustrative Prospective of Solar Energy in Urban Planning: Collection of International Case Studies".

More information on the multi-purpose software tool, LESO-QSV GRID, along with a training package is available on request from LESO/EPFL.

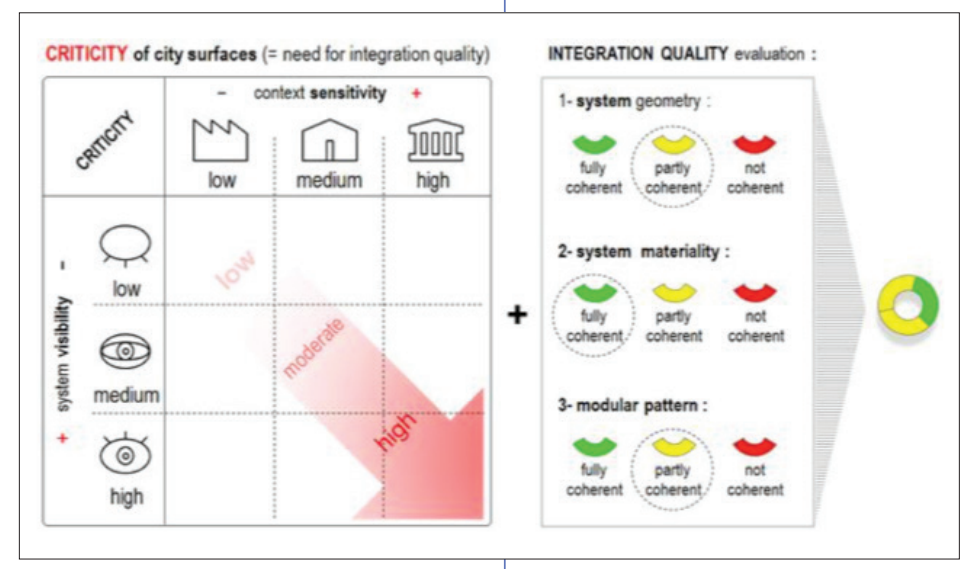

$\Delta$ "Criticity" grid, crossing urban context sensitivity with building surfaces visibility.

Maria Cristina Munari Probst and Christian Roecker of LESO/EPFL presented with the Swedish Innovator of the Year award.

The Netherlands promotion campaign for
renewable heat
technologies
In March a website was launched in the Netherlands to promote renewable heat technologies that qualify for a subsidy under the ISDE scheme ( $w w w . r v o . n l / i s d e)$. The technologies that qualify are solar water heaters, heat pumps, pellet heaters and biomass boilers. The campaign is targeted at consumers who can use the campaign website to find more information on the technologies and the subsidy. The website also includes an overview of the suppliers participating in the campaign and links to their websites. On each supplier's website, consumers can find product information and ask for a quote, which is completed after a qualified installer visits the home. This campaign is hosted by the independent information centre (Milieucentraal) and is part of the Dutch Energy Agreement. Greenpeace has agreed to promote this campaign to all their supporters in the Netherlands. In the future, more organizations will be able join in to support and promote this campaign.

More information can be found at www.duurzamewarmte.nl. 

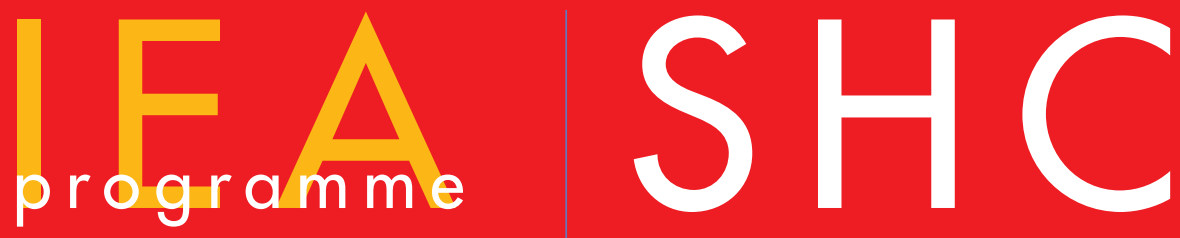

The International Energy Agency was formed in 1974 within the framework of the Organization for Economic Cooperation and Development (OECD) to implement a program of international energy cooperation among its member countries, including collaborative research, development and demonstration projects in new energy technologies. The members of the IEA Solar Heating and Cooling Agreement have initiated a total of 58 R\&D projects (known as Tasks) to advance solar technologies for buildings and industry. The overall Programme is managed by an Executive Committee while the individual Tasks are led by Operating Agents.

\section{Follow IEA SHC on}

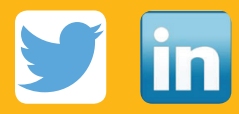

\section{$S \bigcirc L A R U P D A T E$}

The Newsletter of the IEA Solar Heating and Cooling Programme

Vol. 65, May 2017

Prepared for the IEA Solar Heating and Cooling Executive Committee

by

KMGroup, USA

Editor:

Pamela Murphy

This newsletter is intended to provide information

to its readers on the activities of the IEA Solar Heating and Cooling Programme. Its contents do not necessarily reflect the viewpoints or policies of the International Energy Agency or its member countries, the IEA Solar Heating and Cooling Programme members or the participating researchers.

\section{Current Tasks and Operating Agents}

Solar Energy in Urban Planning

Prof. Maria Wall

Dept. of Architecture and Built

Environment

Lund University

P.O. Box 118

SE-22I 00 Lund

SWEDEN

maria.wall@ebd.Ith.se

Solar Heat \& Energy Economics

Mr. Sebastian Herkel

Fraunhofer Institute for Solar

Energy Systems

Heidenhofstr. 2

D-79 II 0 Freiburg

GERMANY

sebastian.herkel@ise.fraunhofer.de

\section{New Generation Solar Cooling} and Heating Systems

Dr. Daniel Mugnier

TECSOL SA

105 av Alfred Kastler - BP 90434

66004 Perpigan Cedex

FRANCE

daniel.mugnier@tecsol.fr

\section{Price Reduction of Solar}

Thermal Systems

Dr. Michael Köhl

Fraunhofer Institute for Solar Energy Sytems Heidenhofstr. 2

D-79 II 0 Freiburg

GERMANY

michael.koehl@ise.fraunhofer.de

Towards the Integration of Large and Cooling (DHC) Network Ms. Sabine Putz

S.O.L.I.D.

Puchstrasse 85

8020 Graz

AUSTRIA

s.putz@solid.at

\section{Building Integrated Solar Envelope} Systems for HVAC and Lighting

Dr. Roberto Fedrizzi

EURAC Research

Institute for Renewable Energy

Via G. Di Vittorio 16

|-39|00 Bolzano

ITALY

roberto.fedrizzi@eurac.edu SHC Systems into District Heating
Solar Standards and Certification

Mr. Jan Erik Nielsen

SolarKey International

Aggerupvej I

DK-4330 Hvalsö

DENMARK

jen@solarkey.dk

\section{Material and Component}

Development for Thermal

Energy Storage

Dr. Wim van Helden

AEE INTEC

Feldgasse 19

A-8200 Gleisdorf

AUSTRIA

w.vanhelden@aee.at

\section{IEA Solor Heating \& Cooling Progrromme Members}

$\begin{array}{llll}\text { AUSTRALIA } & \text { Mr. K. Guthie } & \text { ITALY } & \text { Mr. G. Puglisi } \\ \text { AUSTRIA } & \text { Mr. W. Weiss } & \text { MEXICO } & \text { Dr. W. Rivera } \\ \text { BELGIUM } & \text { Prof. A. De Herde } & \text { NETHERLANDS } & \text { Mr. D van Rijn } \\ \text { CANADA } & \text { Mr. D. McClenahan } & \text { NORWAY } & \text { Dr. M. Meir } \\ \text { CHINA } & \text { Prof. H. Tao } & \text { PORTUGAL } & \text { Mr. J. F. Mendes } \\ \text { DENMARK } & \text { Mr. T. Malmdorf } & \text { RCREEE } & \text { Mr. A. Kraidy } \\ \text { ECI } & \text { Mr. N. Cotton } & \text { SLOVAKIA } & \text { Mr. A. Bobovnický } \\ \text { ECREEE } & \text { Mr. H. Bauer } & \text { SOUTH AFRICA } & \text { Dr. T. Mali } \\ \text { EUROPEAN } & & \text { SPAIN } & \text { Dr. M. Jiménez } \\ \text { COMMISSION } & \text { Mrs. S. Bozsoki } & \text { SWEDEN } & \text { Mr. A. Pettersson } \\ \text { FRANCE } & \text { Mr. P. Kaaijk } & \text { SWITZERLAND } & \text { Mr. A. Eckmanns } \\ \text { GERMANY } & \text { Dr. P. Donat } & \text { TURKEY } & \text { Dr. B. Yesilata } \\ \text { GORD } & \text { Dr. E. Elsarrag } & \text { UNITED KINGDOM } & \text { Dr. P. Dunbabin } \\ \text { ISES } & \text { Mr. J. Mclntosh } & & \end{array}$

CHAIRMAN

Mr. Ken Guthrie

Sustainable Energy Transformation Pty Ltd

148 Spensley Street

Clifton Hill, Victoria 3068

AUSTRALIA

Tel: $+61 / 412178955$

chair@iea-shc.org

\section{SHC SECRETTARIAT}

Ms. Pamela Murphy

KMGroup

913। S. Lake Shore Dr.

Cedar, MI 49621

USA

Tel: + I/23I/620 0634 